\title{
Chromatographic analysis of bio-oil formed in fast pyrolysis of lignocellulosic biomass
}

https://doi.org/10.1515/revac-2020-0108

Received May 21, 2020; accepted July 03, 2020

\begin{abstract}
Fast pyrolysis of lignocellulosic biomass is one of the most promising methods of the production of renewable fuels. However, an optimization of the conditions of bio-oil production is not possible without comprehensive analysis of the composition of formed products. There are several methods for the determination of distribution of products formed during thermal decomposition of biomass with chromatography being the most versatile among them. Although, due to the complex structure of bio-oil (presence of hundreds chemical compounds with different chemical character), an interpretation of the obtained chromatograms is not an easy task. Therefore, the aim of this work is to present an application of different chromatographic methods to the analysis of the composition of the mixture of products formed in high temperature decomposition of lignocellulosic feedstock. It includes pyrolysis-gas chromatography/mass spectrometry (Py-GC/MS), two dimensional gas (GC $x \mathrm{GC}$ ) or liquid chromatography (LC x LC) and initial fractionation of bio-oil components. Moreover, the problems connected with the analysis of biooils formed with the use of various fast pyrolysis reactors and capabilities of multivariate analysis are discussed.
\end{abstract}

Keywords: fast pyrolysis, bio-oil analysis, biofuel, GC-MS, biomass, chromatography

\section{Table of contents}

1. Introduction

2. Chromatographic analysis of bio-oil

2.1. Pyrolysis-gas chromatography/mass spectrometry (Py-GC/MS)

2.2. Types of reactors coupled with GC/MS analysis

2.3. Novel chromatographic methods of bio-oil analysis

*Corresponding author: Jacek Grams, e-mail: jacek.grams@p.lodz.pl Institute of General and Ecological Chemistry, Faculty of Chemistry, Lodz University of Technology, Żeromskiego 116, 90-924 tódź, Poland

\author{
2.4. Application of multivariate analysis \\ 3. Summary \\ 4. References
}

\section{Introduction}

Due to its renewable nature, high abundance, relatively low price and limited impact on the environment, lignocellulosic biomass is considered to be one of the most promising sources of industrially important chemical compounds $[1,2]$. It consists of three main compounds - cellulose, hemicellulose and lignin - accompanied by lower amounts of proteins, waxes, resins and ash, among others [3]. One of the methods of lignocellulosic feedstock conversion is high temperature treatment in an inert gas atmosphere, called pyrolysis [4-8]. This is a complex process consisting of a large number of consecutive reactions [9,10]. Initially, biomass components are subjected to thermal decomposition, followed by depolymerization, dehydration and elimination, among others [11]. Then, formed large reaction intermediates can be transformed to simpler molecules via cracking, decarbonylation, decarboxylation, dehydration or reforming. This results in the production of a liquid fraction (mainly oxygenates), a permanent gas and char [12].

Literature shows that the composition of final products of biomass pyrolysis strictly depends on the conditions of performed reaction [13]. A decrease in the pyrolysis reaction time and increase in heating rate of the feedstock leads to the formation of a higher content of liquid products - bio-oil. An application of short reaction time and fast separation of formed chemical compounds allows a reduction in the efficiency of secondary reactions leading to more effective cracking and limited contribution of permanent gases [14]. In spite of that, the use of heterogeneous catalysts can considerably improve the quality of the obtained mixture and increase selectivity of biomass pyrolysis into desirable products, the composition of bio-oil is still very complex [15-17]. It usually consists of several hundred different chemical substances detectable by currently available analytical techniques.

In order to optimize the production of bio-oil from lignocellulosic feedstock, it is necessary to develop 
analytical methods which would allow an accurate analysis of the composition of the mixture of products formed in fast pyrolysis of lignocellulosic feedstock to be performed. There are several techniques which can be used for this purpose (for example: Nuclear Magnetic Resonance Spectroscopy (NMR) or Fourier-Transform Infrared Spectroscopy (FTIR)) $[18,19]$. However, the performed research indicates that, thanks to the greatest versatility, chromatography is the most widespread among them. Therefore, a further part of this work is focused on the discussion of applications of various chromatographic methods to the analysis of the mixture of products formed in high temperature decomposition of lignocellulosic biomass.

\section{Chromatographic Analysis of Bio-Oil}

\subsection{Pyrolysis-gas chromatography/mass spectrometry (Py-GC/MS)}

Pyrolysis-gas chromatography/mass spectrometry (Py-GC/ MS) is one of the most popular methods used for the analysis of the behavior of biomass in fast pyrolysis process. It consists in decomposition of a small amount of the investigated sample (usually several milligrams) in a microreactor with a controlled heating rate. The use of a small sample weight allows the minimization of the temperature lag during the analysis and heating of biomass with the rate even tens of thousands ${ }^{\circ} \mathrm{C} / \mathrm{s}$, which corresponds to the conditions of fast pyrolysis. In the case of pyrolysis vapor upgrading conducted with the presence of the catalysts, the obtained primary products of thermal decomposition of biomass are passed through a catalyst bed and then, temporarily, collected in the adsorption column at low temperature (i.e. $30^{\circ} \mathrm{C}$ ). In the next step, the absorption column is rapidly heated to about $300^{\circ} \mathrm{C}$ which results in desorption of the collected mixture of pyrolysis products. Subsequently, they are directed to chromatograph for analysis. As mentioned earlier, chromatograms obtained for the mixture of fast pyrolysis products are very complex. Therefore, gas chromatograph should be coupled with a mass spectrometer in order to identify a higher number of compounds formed during biomass decomposition. An interpretation of the obtained mass spectra is commonly performed according to NIST MS library. However, in some cases, the difficulties in data interpretation may be noticed due to low probability of the formation of the suggested compounds. That is why some number of the chromatographic peaks usually remains unidentified.
The information about types of pyrolyzers, chromatographic columns and conditions of GC/MS analysis of the products of fast pyrolysis of lignocellulosic feedstock is presented in Table 1 [20-47]. The comparison of the collected data shows that helium is applied as the carrier gas with a split ratio in the range between 1:7 and 1:100 (with 1:50 and 1:80 the most often used). The injector temperature is usually maintained at the same level as temperature of desorption of reaction products from adsorption column (close to $300^{\circ} \mathrm{C}$ ). The temperature of $\mathrm{GC} / \mathrm{MS}$ interface is slightly lower (about $250^{\circ} \mathrm{C}$ ), while the oven is heated from $30^{\circ} \mathrm{C}$ to $350^{\circ} \mathrm{C}$ (with $280^{\circ} \mathrm{C}$ as the most often used temperature). Mass spectra are collected in $\mathrm{m} / \mathrm{z}$ range from 16 to 800 .

The first limitation of the use of pyrolysis-gas chromatography/mass spectrometry to study fast pyrolysis of biomass can be related to the fact that Py-GC/ MS method does not allow conduction of a continuous process. However, literature shows that the composition of obtained products is in close agreement with that noticed for other bench-scale pyrolyzers [48]. It confirms that this method can be successfully applied to the studies of high temperature decomposition of lignocellulosic feedstock. Additionally, Py-GC/MS does not allow for the collection of formed mixtures of reaction products, which are only temporarily collected in the adsorption column and then passed to gas chromatograph for analysis. That is why determination of mass balance is practically impossible in this case.

It should be also noted that an application of Py-GC/ MS to the analysis of products of fast pyrolysis of biomass cannot guarantee fully quantitative determination of the chemical compounds present in the reaction mixture. However, some quantitative as well as qualitative information can be obtained. It is assumed during Py-GC/MS experiments that there is a linear relationship between change of intensity of chromatographic peaks ascribed to particular reaction products and their amounts. Therefore, changes of peak area percentages observed in the chromatograms obtained for various bio-oil samples can be considered linear with the concentration of formed substances. When the same mass of the feedstock is used in each experiment, the peak intensities observed for particular compounds present in different samples can be compared. This allows for determination of their relative content in the mixture of products. Sun et al. [21] suggested also that direct quantitative analysis with the use of Py-GC/MS can be very difficult due to a large number of identified substances and the lack or high cost of available standards. 
Table 1 Fast pyrolysis of lignocellulosic feedstock performed with the use of Py-GC/MS

\begin{tabular}{|c|c|c|c|}
\hline Instrument & Chromatographic analysis conditions & Reaction/Remarks & Ref. \\
\hline $\begin{array}{l}\text { CDS5200 Pyroprobe } \\
\text { GC/MS (Thermo scientific, } \\
\text { Trace DSQ II) }\end{array}$ & $\begin{array}{l}\text { Column: DB-WAX capillary column }(30 \mathrm{~m} \times 0.25 \mathrm{~mm} \times 0.25 \\
\mu \mathrm{m}) \\
\text { Oven temp.: from } 40 \text { to } 240^{\circ} \mathrm{C} \\
\text { Gas: } \mathrm{He}-1 \mathrm{~mL} / \mathrm{min} \text {, and a } 1: 50 \text { split ratio } \\
\text { MS: } \mathrm{m} / \mathrm{z} 35 \text { to } 450\end{array}$ & $\begin{array}{l}\text { Pyrolysis of cellulose, cellobiose } \\
\text { and glucose; } \\
\text { determination of decomposition } \\
\text { mechanism }\end{array}$ & [20] \\
\hline $\begin{array}{l}\text { EGA/PY-3030D pyrolyzer } \\
\text { GC/MS (GCMS-QP2010 } \\
\text { Ultra; Shimadzu) }\end{array}$ & $\begin{array}{l}\text { Column: RTX-5MS capillary column (Restek; length, } 30 \mathrm{~m} \text {; } \\
\text { internal diameter, } 0.25 \mathrm{~mm} \text {; film thickness, } 0.25 \mu \mathrm{m} \text { ) } \\
\text { Oven temp.: from } 50 \text { to } 260^{\circ} \mathrm{C} \\
\text { Gas: } \mathrm{He}-1.27 \mathrm{~mL} / \mathrm{min} \text { with a split ratio of } 100: 1 \\
\text { MS: } \mathrm{m} / \mathrm{z} 35 \text { to } 500\end{array}$ & $\begin{array}{l}\text { Corn stalk pyrolysis; influence of } \\
\text { catalyst on product distribution }\end{array}$ & [21] \\
\hline $\begin{array}{l}\text { Py- } 5200 \text { HP-R Pyroprobe } \\
\text { VARIAN } 3800 \text { gas } \\
\text { chromatograph and VARIAN } \\
3900 \text { mass spectrometer }\end{array}$ & $\begin{array}{l}\text { Column: } Z B-5 \mathrm{~ms} \text { column }(60 \mathrm{~m} \times 0.25 \mathrm{~mm} \times 0.1 \mu \mathrm{m}) \\
\text { Oven temp.: from } 40 \text { to } 280^{\circ} \mathrm{C} \\
\text { Gas: } \mathrm{He}-1 \mathrm{~mL} / \mathrm{min} \text {, and a } 1: 50 \text { split ratio } \\
\text { MS: } \mathrm{m} / \mathrm{z} 40 \text { to } 500\end{array}$ & $\begin{array}{l}\text { Catalytic upgrading of Elephant } \\
\text { grass pyrolysis vapor }\end{array}$ & [22] \\
\hline $\begin{array}{l}\text { CDS 5200HP Pyroprobe } \\
\text { Perkin Elmer GC/MS (Clarus } \\
560 \text { ) }\end{array}$ & $\begin{array}{l}\text { Column: Elite- } 35 \mathrm{MS} \text { capillary column }(30 \mathrm{~m} \times 0.25 \mathrm{~mm} \text { i.d., } \\
0.25 \mu \mathrm{m} \text { film thickness) } \\
\text { Oven temp.: from } 40 \text { to } 280^{\circ} \mathrm{C} \\
\text { Gas: He (flow rate }- \text { no data), } 1: 50 \text { split ratio } \\
\text { MS: no data }\end{array}$ & $\begin{array}{l}\text { Catalytic fast pyrolysis of pine } \\
\text { wood; } \\
\text { yields of major pyrolytic } \\
\text { products were determined by an } \\
\text { external calibration method }\end{array}$ & [23] \\
\hline $\begin{array}{l}\text { CDS } 5200 \text { Pyroprobe } \\
\text { Agilent } 7890 \mathrm{~A} / 5975 \mathrm{C} \\
\text { gas chromatograph/mass } \\
\text { spectrometer }\end{array}$ & $\begin{array}{l}\text { Column: HP-5MS }(30 \mathrm{~m} \times 0.25 \mathrm{~mm} \times 0.25 \mu \mathrm{m}) \\
\text { Oven temp.: from } 40 \text { to } 280^{\circ} \mathrm{C} \\
\text { Gas: } \mathrm{He}-1 \mathrm{~mL} / \mathrm{min} \text { and a split ratio of } 1: 80 \\
\text { MS: no data }\end{array}$ & $\begin{array}{l}\text { Catalytic fast pyrolysis of } \\
\text { bamboo residue }\end{array}$ & [24] \\
\hline $\begin{array}{l}\text { CDS } 5250 \text { Pyroprobe } \\
\text { GC/MS (Thermo Scientific, } \\
\text { Trace DSQ II) }\end{array}$ & $\begin{array}{l}\text { Column: TR-5MS capillary column }(30 \mathrm{~m} \times 0.25 \mathrm{~mm} \text { i.d., } \\
0.25 \mu \mathrm{m} \text { film thickness) } \\
\text { Oven temp.: from } 40 \text { to } 280^{\circ} \mathrm{C} \\
\text { Gas: } \mathrm{He}-1 \mathrm{~mL} / \mathrm{min} \text { and a split ratio of } 1: 80 \\
\text { MS: } \mathrm{m} / \mathrm{z} 20 \text { to } 400\end{array}$ & $\begin{array}{l}\text { Catalytic upgrading of poplar } \\
\text { wood fast pyrolysis vapors with } \\
\text { nano metal oxides }\end{array}$ & [25] \\
\hline $\begin{array}{l}\text { CDS } 5200 \text { Pyroprobe } \\
\text { Agilent } 7890 \mathrm{~A} / 5975 \mathrm{C} \\
\text { gas chromatograph/mass } \\
\text { spectrometer }\end{array}$ & $\begin{array}{l}\text { Column: HP-5MS capillary column }(30 \mathrm{~m} \times 0.25 \mathrm{~mm}, 0.25 \\
\mu \mathrm{m} \text { film thickness) } \\
\text { Oven temp.: from } 30 \text { to } 280^{\circ} \mathrm{C} \\
\text { Gas: He (flow rate - no data), } 1: 50 \text { split ratio } \\
\text { MS: } \mathrm{m} / \mathrm{z} 40 \text { to } 400\end{array}$ & $\begin{array}{l}\text { Hydro-pyrolysis and catalytic } \\
\text { upgrading of biomass }\end{array}$ & [26] \\
\hline $\begin{array}{l}\text { CDS } 5200 \text { Pyroprobe } \\
\text { Agilent } 7890 \mathrm{~A} / 5975 \mathrm{C} \\
\text { gas chromatograph/mass } \\
\text { spectrometer }\end{array}$ & $\begin{array}{l}\text { Column: RTX-5MS capillary column }(30 \mathrm{~m} \times 0.25 \mathrm{~mm} \text { i.d., } \\
0.25 \mu \mathrm{m} \text { film thickness) } \\
\text { Oven temp.: from } 30 \text { to } 280^{\circ} \mathrm{C} \\
\text { Gas: } \mathrm{He}-15.28 \mathrm{~mL} / \mathrm{min}, 1: 50 \text { split ratio } \\
\text { MS: } \mathrm{m} / \mathrm{z} 40 \text { to } 400\end{array}$ & $\begin{array}{l}\text { Hydro-pyrolysis of biomass and } \\
\text { online catalytic vapor upgrading }\end{array}$ & [27] \\
\hline $\begin{array}{l}\text { CDS } 5200 \text { Pyroprobe } \\
\text { Agilent } 7890 \mathrm{~A} / 5975 \mathrm{C} \\
\text { gas chromatograph/mass } \\
\text { spectrometer }\end{array}$ & $\begin{array}{l}\text { Column: HP-5MS capillary column }(30 \mathrm{~m} \times 0.25 \mathrm{~mm}, 0.25 \\
\mu \mathrm{m} \text { film thickness) } \\
\text { Oven temp.: from } 50 \text { to } 290^{\circ} \mathrm{C} \\
\text { Gas: } \mathrm{He}-1 \mathrm{~mL} / \mathrm{min} \text { and a split ratio of } 1: 60 \\
\text { MS: no data }\end{array}$ & $\begin{array}{l}\text { Catalytic pyrolysis of pine } \\
\text { sawdust }\end{array}$ & [28] \\
\hline $\begin{array}{l}\text { CDS } 5250 \text { Pyroprobe } \\
\text { GC/MS (Thermo Scientific, } \\
\text { Trace DSQ II) }\end{array}$ & $\begin{array}{l}\text { Column: TR-35MS capillary column }(30 \mathrm{~m} \times 0.25 \mathrm{~mm} \text { i.d., } \\
0.25 \mu \mathrm{m} \text { film thickness) } \\
\text { Oven temp.: from } 40 \text { to } 280^{\circ} \mathrm{C} \\
\text { Gas: } \mathrm{He}-1 \mathrm{~mL} / \mathrm{min} \text { and a } 1: 80 \text { split ratio } \\
\text { MS: } \mathrm{m} / \mathrm{z} \text { from } 20 \text { to } 400\end{array}$ & $\begin{array}{l}\text { Fast pyrolysis of poplar } \\
\text { wood followed with catalytic } \\
\text { upgrading of the pyrolysis } \\
\text { vapors }\end{array}$ & [29] \\
\hline $\begin{array}{l}\text { CDS } 5200 \text { Pyroprobe } \\
\text { Agilent } 7890 \mathrm{~A} / 5975 \mathrm{C} \\
\text { gas chromatograph/mass } \\
\text { spectrometer }\end{array}$ & $\begin{array}{l}\text { Column: HP-5MS capillary column }(30 \mathrm{~m} \times 0.25 \mathrm{~mm}, 0.25 \\
\mu \mathrm{m} \text { film thickness) } \\
\text { Oven temp.: no data } \\
\text { Gas: He }-1 \mathrm{~mL} / \mathrm{min} \text { and a } 1: 80 \text { split ratio } \\
\text { MS: } \mathrm{m} / \mathrm{z} 35 \text { to } 550\end{array}$ & $\begin{array}{l}\text { Catalytic upgrading of vapors of } \\
\text { fast pyrolyzed corn stover }\end{array}$ & [30] \\
\hline
\end{tabular}




\begin{tabular}{|c|c|c|c|}
\hline $\begin{array}{l}\text { CDS 5200HP } \\
\text { Pyrolyzer } \\
\text { PerkinElmer Clarus } 560 \\
\text { GC/MS }\end{array}$ & $\begin{array}{l}\text { Column: Elite-35MS capillary column }(30 \mathrm{~m} \times 0.25 \mathrm{~mm} \text { i.d., } \\
0.25 \mu \mathrm{m} \text { film thickness) } \\
\text { Oven temp.: from } 40 \text { to } 280^{\circ} \mathrm{C} \\
\text { Gas: He (flow rate }- \text { no data), split ratio of } 1: 80 \\
\text { MS: no data }\end{array}$ & $\begin{array}{l}\text { Fast pyrolysis of pine wood } \\
\text { followed by catalytic cracking } \\
\text { of pyrolysis vapors over zeolite } \\
\text { catalysts; } \\
\text { quantitative determination of } \\
\text { important pyrolytic compounds }\end{array}$ & [31] \\
\hline $\begin{array}{l}\text { CDS } 5250 \text { Pyroprobe } \\
\text { GC/MS (Thermo Scientific, } \\
\text { Trace DSQ II) }\end{array}$ & $\begin{array}{l}\text { Column: TR-35MS capillary column ( } 30 \mathrm{~m} \text { x } 0.25 \mathrm{~mm} \text { i.d., } \\
0.25 \mu \mathrm{m} \text { film thickness) } \\
\text { Oven temp.: from } 40 \text { to } 280^{\circ} \mathrm{C} \\
\text { Gas: } \mathrm{He}-1 \mathrm{~mL} / \mathrm{min} \text { and a } 1: 80 \text { split ratio } \\
\text { MS: } \mathrm{m} / \mathrm{z} \text { from } 20 \text { to } 400\end{array}$ & $\begin{array}{l}\text { Catalytic upgrading of poplar } \\
\text { wood fast pyrolysis vapors }\end{array}$ & [32] \\
\hline $\begin{array}{l}\text { CDS } 5200 \text { Pyroprobe } \\
\text { Agilent } 7890 \mathrm{~A} / 5975 \mathrm{C} \\
\text { gas chromatograph/mass } \\
\text { spectrometer }\end{array}$ & $\begin{array}{l}\text { Column: DB1701 }(60 \mathrm{~m} \times 0.25 \mathrm{~mm} \times 0.1 \mu \mathrm{m}) \\
\text { Oven temp.: from } 45 \text { to } 280^{\circ} \mathrm{C} \\
\text { Gas: He }-1 \mathrm{ml} / \mathrm{min} \text {, split ratio }- \text { no data } \\
\text { MS: no data }\end{array}$ & $\begin{array}{l}\text { Pyrolysis of sinapyl and } \\
\text { coniferyl alcohol, determination } \\
\text { of sinapyl:guaiacyl (S:G) ratios }\end{array}$ & [33] \\
\hline $\begin{array}{l}\text { CDS } 5200 \mathrm{HP} \\
\text { Pyroprobe } \\
\text { Agilent } 7890 / 5975 \mathrm{C} \text { gas } \\
\text { chromatograph/mass } \\
\text { spectrometer }\end{array}$ & $\begin{array}{l}\text { Column: Agilent HP- } 5 \text { capillary } \\
\text { Oven temp.: from } 40 \text { to } 280^{\circ} \mathrm{C} \\
\text { Gas: He (flow rate }- \text { no data), } 100: 1 \text { split ratio } \\
\text { MS: } \mathrm{m} / \mathrm{z} 50 \text { to } 400\end{array}$ & $\begin{array}{l}\text { Catalytic upgrading of sawdust } \\
\text { fast pyrolysis vapor }\end{array}$ & [34] \\
\hline $\begin{array}{l}\text { CDS } 5250 \text { Pyroprobe } \\
\text { GC/MS (Thermo Scientific, } \\
\text { Trace DSQ II) }\end{array}$ & $\begin{array}{l}\text { Column: TG-5MS capillary column }(30 \mathrm{~m} \times 0.25 \mathrm{~mm} \text { i.d } \times \\
0.25 \mu \mathrm{m} \text { film thickness) } \\
\text { Oven temp.: from } 40 \text { to } 280^{\circ} \mathrm{C} \\
\text { Gas: } \mathrm{He}-1 \mathrm{~mL} / \mathrm{min} \text { and a } 1: 40 \text { split ratio } \\
\text { MS: } \mathrm{m} / \mathrm{z} 45 \text { to } 650\end{array}$ & Pyrolysis of soybean stalk & [35] \\
\hline $\begin{array}{l}\text { CDS } 5200 \text { Pyroprobe } \\
\text { Agilent } 7890 \mathrm{~A} / 5975 \mathrm{C} \\
\text { gas chromatograph/mass } \\
\text { spectrometer }\end{array}$ & $\begin{array}{l}\text { Column: HP5MS capillary column ( } 30 \text { m length with } 0.25 \\
\text { mm inner diameter) } \\
\text { Oven temp.: from } 50 \text { to } 300^{\circ} \mathrm{C} \\
\text { Gas: } \mathrm{He}-30 \mathrm{~mL} / \mathrm{min} \text { and a } 1: 50 \text { split ratio } \\
\text { MS: } \mathrm{m} / \mathrm{z} 35 \text { to } 400\end{array}$ & $\begin{array}{l}\text { Red mud and beechwood } \\
\text { co-processing for the } \\
\text { upgrading of fast pyrolysis } \\
\text { vapours }\end{array}$ & [36] \\
\hline $\begin{array}{l}\text { CDS } 5200 \mathrm{HP} / \mathrm{HT} \text { pyroprobe } \\
\text { GC, model K } 8880181 \text { by } \\
\text { ThermoFisher and MS, } \\
\text { model DSQIl by Thermo } \\
\text { Scientific) }\end{array}$ & $\begin{array}{l}\text { Column: Rxi-5 ms, } 30 \mathrm{~m} \times 0.25 \mathrm{~mm}, 0.25 \mu \mathrm{m} \text { film thickness } \\
\text { Oven temp.: from } 35 \text { to } 275^{\circ} \mathrm{C} \\
\text { Gas: He (flow rate - no data), split ratio - no data } \\
\text { MS: no data }\end{array}$ & $\begin{array}{l}\text { Fast pyrolysis of bio-oil from rice } \\
\text { straw }\end{array}$ & [37] \\
\hline $\begin{array}{l}\text { CDS } 5200 \text { Pyroprobe } \\
\text { Agilent } 7890 / 5975 \text { gas } \\
\text { chromatograph/mass } \\
\text { spectrometer }\end{array}$ & $\begin{array}{l}\text { Column: HP-5MS capillary column }(0.25 \mathrm{~mm} \times 0.25 \mu \mathrm{m} \times 30 \\
\mathrm{m}) \\
\text { Oven temp.: no data } \\
\text { Gas: He }-1 \mathrm{~mL} / \mathrm{min} \text { and a } 1: 80 \text { split ratio } \\
\text { MS: no data }\end{array}$ & $\begin{array}{l}\text { Catalytic fast pyrolysis of rice } \\
\text { husk }\end{array}$ & [38] \\
\hline $\begin{array}{l}\text { CDS } 5000 \text { Pyroprobe } \\
\text { Agilent } 7890 / 5975 \text { gas } \\
\text { chromatograph/mass } \\
\text { spectrometer }\end{array}$ & $\begin{array}{l}\text { Column: HP- } 5 \text { MS capillary column }(0.25 \mathrm{~mm} \times 0.25 \mu \mathrm{m} \times 30 \\
\mathrm{m}) \\
\text { Oven temp.: from } 50 \text { to } 300^{\circ} \mathrm{C} \\
\text { Gas: } \mathrm{He}-30 \mathrm{~mL} / \mathrm{min} \text { and a } 1: 50 \text { split ratio } \\
\text { MS: } \mathrm{m} / \mathrm{z} 35 \text { to } 550\end{array}$ & $\begin{array}{l}\text { Catalytic fast pyrolysis of } \\
\text { pinewood }\end{array}$ & [39] \\
\hline $\begin{array}{l}\text { PY-2020iD Pyroprobe } \\
\text { GCMS-QP2010 Shimadzu }\end{array}$ & $\begin{array}{l}\text { Column: } 30 \mathrm{~m} \times 0.25 \mathrm{~mm} \text { Ultra alloy } 5 \text { (i.d., } 0.25 \mu \mathrm{m} \text { film } \\
\text { thickness) } \\
\text { Oven temp.: from } 50 \text { to } 350^{\circ} \mathrm{C} \\
\text { Gas: } \mathrm{He}-1.3 \mathrm{~mL} / \mathrm{min} \text { and a } 1: 50 \text { split ratio } \\
\text { MS: } \mathrm{m} / \mathrm{z} 20 \text { to } 800\end{array}$ & $\begin{array}{l}\text { Catalytic pyrolysis of Jatropha } \\
\text { wastes }\end{array}$ & [40] \\
\hline $\begin{array}{l}\text { PY-2020iD Pyroprobe } \\
\text { GCMS-QP2010 Shimadzu }\end{array}$ & $\begin{array}{l}\text { Column: } 30 \mathrm{~m} \times 0.25 \mathrm{~mm} \text { Ultra alloy } 5 \text { (i.d., } 0.25 \mu \mathrm{m} \text { film } \\
\text { thickness) } \\
\text { Oven temp.: from } 50 \text { to } 350^{\circ} \mathrm{C} \\
\text { Gas: } \mathrm{He}-1.3 \mathrm{~mL} / \mathrm{min} \text { and a } 1: 50 \text { split ratio } \\
\text { MS: } \mathrm{m} / \mathrm{z} 20 \text { to } 800\end{array}$ & $\begin{array}{l}\text { Aromatic formation from } \\
\text { catalytic fast pyrolysis of } \\
\text { Jatropha residues }\end{array}$ & [41] \\
\hline
\end{tabular}




\begin{tabular}{|c|c|c|c|}
\hline $\begin{array}{l}\text { PY-2020iD Pyroprobe } \\
\text { GCMS-QP2010 Shimadzu }\end{array}$ & $\begin{array}{l}\text { Column: } 30 \mathrm{~m} \times 0.25 \mathrm{~mm} \text { Ultra alloy } 5 \text { (i.d., } 0.25 \mu \mathrm{m} \text { film } \\
\text { thickness) } \\
\text { Oven temp.: from } 50 \text { to } 350^{\circ} \mathrm{C} \\
\text { Gas: } \mathrm{He}-1.3 \mathrm{~mL} / \mathrm{min} \text { and a } 1: 50 \text { split ratio } \\
\text { MS: } \mathrm{m} / \mathrm{z} 20 \text { to } 800\end{array}$ & $\begin{array}{l}\text { Catalytic upgrading pyrolysis } \\
\text { vapors of Jatropha waste using } \\
\text { metal catalysts }\end{array}$ & [42] \\
\hline $\begin{array}{l}\text { CDS } 5200 \text { Pyroprobe } \\
\text { GC/MS } \\
\text { QP2010 Plus, Shimadzu }\end{array}$ & $\begin{array}{l}\text { Column: RTX-1701 }(60 \mathrm{~m} \times 0.25 \mathrm{~mm} \times 0.25 \mu \mathrm{m}) \\
\text { Oven temp.: from } 45 \text { to } 280^{\circ} \mathrm{C} \\
\text { Gas: He }-1 \mathrm{~mL} / \mathrm{min} \text { and a } 1: 10 \text { split ratio } \\
\text { MS: no data }\end{array}$ & $\begin{array}{l}\text { Catalytic upgrading of fast } \\
\text { hydro-pyrolysis vapors from } \\
\text { industrial Kraft lignins }\end{array}$ & [43] \\
\hline $\begin{array}{l}\text { Pyrola2000 } \\
\text { GC (Trace GC Ultra), MS } \\
\text { (ISQ) and FID }\end{array}$ & $\begin{array}{l}\text { Column: Zebron }{ }^{\mathrm{TM}} \mathrm{ZB}-5 \mathrm{MS}(30 \mathrm{~m} \times 0.25 \mathrm{~mm} \times 0.25 \mu \mathrm{m}) \\
\text { Oven temp.: from } 60 \text { to } 265^{\circ} \mathrm{C} \\
\text { Gas: } \mathrm{He}-1.5 \mathrm{~mL} / \mathrm{min} \text { and a } 1: 7 \text { split ratio } \\
\text { MS: } \mathrm{m} / \mathrm{z} 16 \text { to } 650\end{array}$ & Pyrolysis of cellulose and xylan & [44] \\
\hline $\begin{array}{l}\text { CDS } 5200 \text { Pyroprobe } \\
\text { Agilent } 7890 \mathrm{~A} / 5975 \mathrm{C} \\
\text { gas chromatograph/mass } \\
\text { spectrometer }\end{array}$ & $\begin{array}{l}\text { Column: RTX-5MS capillary column }(30 \mathrm{~m} \times 0.25 \mathrm{~mm} \text { i.d., } \\
0.25 \mu \mathrm{m} \text { film thickness }) \\
\text { Oven temp.: from } 30 \text { to } 280^{\circ} \mathrm{C} \\
\text { Gas: He }-15.28 \mathrm{~mL} / \mathrm{min}, 1: 50 \text { split ratio } \\
\text { MS: } \mathrm{m} / \mathrm{z} 40 \text { to } 400\end{array}$ & $\begin{array}{l}\text { Hydropyrolysis of Miscanthus } \mathrm{x} \\
\text { giganteus and online catalytic } \\
\text { vapour upgrading }\end{array}$ & [45] \\
\hline $\begin{array}{l}\text { CDS } 5200 \text { Pyroprobe } \\
\text { Agilent } 7890 \mathrm{~A} / 5975 \mathrm{C} \\
\text { gas chromatograph/mass } \\
\text { spectrometer }\end{array}$ & $\begin{array}{l}\text { Column: RTX-5MS capillary column }(30 \mathrm{~m} \times 0.25 \mathrm{~mm} \text { i.d., } \\
0.25 \mu \mathrm{m} \text { film thickness }) \\
\text { Oven temp.: from } 30 \text { to } 280^{\circ} \mathrm{C} \\
\text { Gas: } \mathrm{He}-15 \mathrm{~mL} / \mathrm{min}, 1: 50 \text { split ratio } \\
\text { MS: } \mathrm{m} / \mathrm{z} 40 \text { to } 400\end{array}$ & $\begin{array}{l}\text { Catalytic upgrading of cellulose } \\
\text { fast pyrolysis vapors }\end{array}$ & [46] \\
\hline $\begin{array}{l}\text { CDS } 5200 \text { Pyroprobe } \\
\text { Agilent } 7890 \mathrm{~A} / 5975 \mathrm{C} \\
\text { gas chromatograph/mass } \\
\text { spectrometer }\end{array}$ & $\begin{array}{l}\text { Column: RTX-5MS capillary column }(30 \mathrm{~m} \times 0.25 \mathrm{~mm} \text { i.d., } \\
0.25 \mu \mathrm{m} \text { film thickness) } \\
\text { Oven temp.: from } 30 \text { to } 280^{\circ} \mathrm{C} \\
\text { Gas: } \mathrm{He}-15 \mathrm{~mL} / \mathrm{min}, 1: 50 \text { split ratio } \\
\text { MS: } \mathrm{m} / \mathrm{z} 40 \text { to } 400\end{array}$ & $\begin{array}{l}\text { Catalytic upgrading of cellulose } \\
\text { fast pyrolysis vapors }\end{array}$ & [47] \\
\hline
\end{tabular}

On the other hand, Lu et al. [23] reported that Py-GC/ MS can be useful in quantitative analysis when the measurementsare only focused on a small group ofselected compounds. In this case, external calibration method was applied. It allowed the determination of the content of 14 different chemical compounds (for example 2-methoxy-4methyl phenol as a representative of phenolics). The use of external calibration method for the analysis of the products of catalytic fast pyrolysis of biomass was also described in Ref. [31]. These studies were devoted to the production of aromatic hydrocarbons. That is why the concentration of 5 major aromatic compounds, such as benzene, toluene, xylene, naphthalene and 2-methylnaphthalene, was determined. Moreover, Harman-Ware et al. [33] applied Py-GC/MS to a determination of the ratio of sinapyl and coniferyl alcohol in pyrolyzed lignin. It was possible due to the selection of several phenolic compounds used as markers of mentioned lignin components.

Due to the problems with quantitative determination of the products of fast pyrolysis of lignocellulosic biomass, the Py-GC/MS studies are mainly focused on the qualitative aspects of the composition of bio-oil and comparison of the contribution of its components. In spite of that, the interpretation of the obtained results is not an easy task. The large number of pyrolysis products generates difficulties related to description of the composition of analyzed mixture.

Generally, in the first step of Py-GC/MS experiment, the total intensity of chromatographic peaks is determined. It allows for comparison of the efficiency of the production of a liquid fraction. Then, identified compounds are divided into several groups based on differences in their chemical structure. Different ways of the mentioned division are presented in Table 2. It is demonstrated that hydrocarbons, phenols, carboxylic acids, aldehydes, alcohols and ketones are the most popular groups of analyzed products. Some researchers also include carbohydrates, esters, ethers, N-containing compounds, etc. It is worth noticing that some part of the characterized substances are not assigned to any of the groups and collected as "others". This may result from their complex structure (presence of different functional groups) or impossibility of identification.

In the next step, an interpretation of the results is focused on the analysis of the contribution of particular compounds interesting from scientific or industrial points of view. The main groups of products can be divided into more specific ones. For example, Zhang et al. [34] divided hydrocarbons into light hydrocarbon and aromatics. On the other hand, Vichaphund et al. [40] focused on 
Table 2 The most popular groups of products formed in fast pyrolysis of lignocellulosic biomass identified on the basis of Py-GC/MS experiments

\begin{tabular}{|c|c|c|c|c|c|c|c|c|c|c|c|}
\hline \multirow[t]{2}{*}{ Group } & \multicolumn{11}{|c|}{ Ref. } \\
\hline & {$[21]$} & [24] & {$[25]$} & [26] & [29] & [30] & [34] & [39] & [40] & [43] & [47] \\
\hline Aldehydes & + & + & + & & + & & + & + & + & + & + \\
\hline Acids & + & + & + & + & + & + & + & + & + & + & + \\
\hline Alcohols & + & + & + & + & & + & & + & + & + & + \\
\hline Anhydrosugars & & & + & & & & & & & & \\
\hline Carbohydrates & + & & & & + & + & & + & & & + \\
\hline Ketones & + & + & + & & + & & + & + & + & + & + \\
\hline Hydrocarbons & + & + & + & + & + & + & + & & + & + & + \\
\hline Phenols & + & + & + & + & + & + & + & + & & + & \\
\hline Furans & & + & + & + & + & + & + & + & & & \\
\hline Esters & + & + & & & & + & & + & + & + & + \\
\hline Ethers & & & & & & & & & + & + & + \\
\hline Pyrans & & & & & & & & + & & & \\
\hline N-compounds & + & & & & & & & + & + & & \\
\hline Others & + & + & + & & + & + & & & & + & \\
\hline
\end{tabular}

Table 3 Exemplary composition of bio-oils formed in fast prylolysis of lignocellulosic biomass

\begin{tabular}{lll}
\hline Process & Composition of bio-oil \\
\hline Hydro-pyrolysis and & phenolics- phenol, 2-methyl-phenol, 4-methyl phenol, 2-methoxy-phenol, 2-methoxy-4-methyl-phenol, \\
$\begin{array}{l}\text { catalytic upgrading } \\
\text { of biomass }\end{array}$ & 2-methoxy-4-vinyl-phenol and 2,6-dimethoxyphenol \\
& $\begin{array}{l}\text { aromatic hydrocarbons - benzene, toluene, p-xylene and 1-ethyl-methyl-benzene } \\
\text { cyclo-alkanes - cyclohexane, methyl-cyclohexane, 1,2-dimethyl-cyclohexane, ethyl-cyclohexane and } \\
\\
\text { propyl-cyclohexane } \\
\\
\text { furans - 2,3-dihydrobenzofuran, furfural, 2-ethyl-5-methyl-furan, furan and 2-methyl-furan } \\
\text { alcohols - butanol and pentanol }\end{array}$ \\
\hline
\end{tabular}

Fast pyrolysis of poplar wood followed with catalytic upgrading of the pyrolysis vapors phenolics - phenol, 2-methyl-phenol, 4-methyl phenol, 2-methoxy-phenol, 2-methoxy-4-

\section{3,5-dimethoxyacetophenone, and 4-allyl-2,6-dimethoxyphenol}

furans - furan, 2-methyl-furan, furfural and 5-hydroxymethyl-furfural

carbonlyl compounds - acetaldehyde, 2-propenal, hydroxyacetaldehyde

carboxylic acids - acetic acids, propanoic acid and acetoxyacetic acid

hydrocarbons - benzene, toluene, p-xylene, 1-ethynyl-4-methyl-benzene

cyclopentanones - 2-cyclopentanone, 2-cyclopentanene-1,4-dione, 1,2-cyclopentanedione and corylon

Catalytic upgrading of sawdust fast pyrolysis vapor

phenolics - phenol, 2-methyl-phenol, 3-methyl-phenol, 2-methoxy-phenol, 2-methoxy-4-vinyl-phenol, 2,6-dimethoxyphenol, 2,6-dimethoxy-4-(2-propenyl)- phenol, 2-methoxy-4-(1-propenyl)- phenol and 4-(3-hydroxy-1-propenyl)-2-methoxy-phenol aldehydes - acetaldehyde, propanal, 2,3-dimethyl-pentanal, 4-methyl-2,5-dimethoxybenzaldehyde, 4-hydroxy-3,5-dimethoxybenzaldehyde, 2-methyl-pentanal and 2-methyl-propanal ketones - 1,2-cyclopentanedione, 1-(4-hydroxy-3,5-dimethoxyphenyl)-ethanone, 2-pentanone, 3-pentanone, cyclopentanone, 2-methyl-2-cyclopenten-1-one, 3-methyl-2-cyclopenten-1-one, 2,3-dimethyl-2-cyclopenten-1-one and 3-methyl-2-heptanone furans- -2-methyl-furan, 2,5-dimethyl-furan and furfural light hydrocarbons - 1,3-butadiene, 2-methyl-1-buten-3-yne, 1-methoxy-1-propene, 1,3-pentadiene, 1,4-cyclohexadiene, 1,4-hexadiene, 2-methyl-1-butene, 1,3-cyclopentadiene, 1,2-dimethylcyclopropane, 1-methyl-1,3-cyclopentadiene, 3-methylene-cyclopentene and 1,2-dimethylcyclopropene aromatic hydrocarbons - benzene, toluene, 1,3-dimethylbenzene, ethylbenzene, styrene and indene 
aliphatic and aromatic compounds, while Grams et al. [47] identified olefins, paraffins, aromatics and cyclic hydrocarbons.

Subsequently, an analysis of the particular substances within the most interesting subgroups takes place. Liu et al. [26] in their work devoted to hydro-pyrolysis of biomass discussed the effect of reaction conditions, presence of catalyst and type of feedstock on the content of phenolic compounds (including phenol and its derivatives, such as: 2-methyl-phenol, 4-methyl-phenol, 2-methoxy-phenol, 2-methoxy-4-methyl-phenol, 2-methoxy-4-vinyl-phenol and 2,6-dimethoxyphenol), aromatic hydrocarbons (benzene, toluene, p-xylene and 1-ethyl-methyl-benzene), cyclo-alkanes (i.e. cyclohexane, methyl-cyclohexane, 1,2-dimethyl-cyclohexane, ethyl-cyclohexane and propylcyclohexane), furans (2,3-dihydrobenzofuran, furfural, 2-ethyl-5-methyl-furan, furan and 2-methyl-furan) and alcohols (butanol and pentanol) (Table 3). Xue at al. [24] studied catalytic fast pyrolysis of bamboo residue and focused on the identification of phenols (phenol, xylenol, ethyl phenol, benzenetriol, syringol, metoxyphenol, vinyl-methoxy phenol, methyl methoxyphenol and ethyl methoxyphenol), while Zhang et al. [30] determined contribution of not only phenols, but also hydrocarbons (such as: benzene, toluene, xylene, indene and polycyclic aromatic hydrocarbons (PAHs)).

The other works also underlined complex composition of bio-oil formed in fast pyrolysis of biomass. Lu et al. [29] compared the intensity of peaks corresponding to the presence of 11 phenolic compounds and 4 hydrocarbons, among others. On the other hand, Zhang et al. [34] distinguished 7 aldehydes, 9 ketones, 3 furans, 6 aromatic and 12 light hydrocarbons (Table 3). The presented data suggests that detailed interpretation of the results obtained by Py-GC/MS is very difficult and probably not necessary. Therefore, researchers focused rather on the identification of the major bio-oil components which are the most valuable from the industrial point of view or undesirable ones (taking into account their toxic character or instability).

\subsection{Types of reactors coupled with GC/MS analysis}

The most popular way of the analysis of bio-oil formed in the fast pyrolysis of biomass is related with the use of setup consisted of Pyroprobe pyrolyzer coupled with GC/ MS as an analytical tool. However, literature shows that thermal decomposition of lignocellulosic feedstock can also be performed with the use of various types of chemical reactors, for example fixed bed, fluidized bed, moving bed, conical spouted bed, multi-zone, etc. (Table 4) [14, 18, 49-55]. The majority of them operate in continuous mode, which is widely applied in the industrial processes of biomass conversion. This creates a need for development of methods allowing transport of produced bio-oil from the reaction system to the chromatograph. It appears that the reaction mixture can be passed directly (on-line) to GC/MS system or condensed by condenser units in order to transform the pyrolysis products to the liquid phase. Then, the obtained samples of bio-oil are directed to the chromatograph by separate injections.

For example, Amutio et al. [49] condensed bio-oil formed in a conical spouted bed reactor by double-shell tube condenser cooled by tap water. They also used two coalescence filters in order to ensure the recovery of heavy molecules. Similarly, the use of condensers for transformation of pyrolysis products into liquid phase was reported in Refs. [52,54].

Generally, an identification of the collected products is performed according to the same procedure as that used during Py-GC/MS analysis described in the previous chapter. However, slight differences in the measurement parameters can be observed in this case (Table 4). The temperature of $\mathrm{GC} / \mathrm{MS}$ oven varied from $40^{\circ} \mathrm{C}$ to $330^{\circ} \mathrm{C}$, while split ratio ranged from 1:4 to 1:100. Mass spectra were collected in $\mathrm{m} / \mathrm{z}$ range from $0-1000$.

\subsection{Novel chromatographic methods of bio-oil analysis}

Complex nature and large variety of chemical compounds present in the mixture of products of fast pyrolysis of lignocellulosic biomass result in the problems with identification of bio-oil components. Despite high versatility of $\mathrm{GC} / \mathrm{MS}$, this technique does not allow for identification of all substances formed during decomposition of lignocellulosic feedstock (for example those which possess high polarity, low volatility or poor thermal stability). That is why, there is a need to design new complementary methods that would fill the gaps in this field. Taking that into account, researchers focused on the development of novel chromatographic methods devoted to determination of the composition of bio-oil formed in high temperature conversion of biomass. Previously performed studies were described in several review papers $[19,56]$. Moreover, the examples of the conducted investigations are presented in Table 5 [57-67].

Due to complex composition of bio-oil and difficulties in the identification of its components, the various methods 
Table 4 Fast pyrolysis of lignocellulosic feedstock performed with the use of various reactors

\begin{tabular}{|c|c|c|c|}
\hline Reactor & Chromatographic analysis conditions & Reaction/Remarks & Ref. \\
\hline blade-type reactor & $\begin{array}{l}\text { GC-MS (Agilent } 6890 \mathrm{~N} \mathrm{GC} 5973 \mathrm{MS} \text { ), column (NSP5 Inert } 30 \mathrm{~m} \\
\times 0.25 \mathrm{~mm} \times 0.25 \mu \mathrm{m}) \text {, oven } 40-200^{\circ} \mathrm{C} \text {, He (1 mL/min, Inlet: } \\
\left.250^{\circ} \mathrm{C} \text {, split ratio } 1: 4\right), \mathrm{m} / \mathrm{z} 29-550\end{array}$ & $\begin{array}{l}\text { continuous fast pyrolysis of } \\
\text { Prosopis juliflora }\end{array}$ & [18] \\
\hline $\begin{array}{l}\text { conical spouted bed } \\
\text { reactor }\end{array}$ & $\begin{array}{l}\text { Reactor outlet stream monitored prior to condensation using } \\
\text { GC (Varian 3900) equipped with a flame ionization detector } \\
\text { (FID), line from the reactor outlet to the chromatograph was } \\
\text { heated to a temperature of } 280^{\circ} \mathrm{C} \text {, bio-oil recovered in the } \\
\text { condenser and filters was investigated by GC/MS (Shimadzu } \\
\text { UP-2010S) }\end{array}$ & $\begin{array}{l}\text { fast pyrolysis of Eucalyptus } \\
\text { globulus wood, bark and leaves }\end{array}$ & [49] \\
\hline $\begin{array}{l}\text { multi-zone fixed bed } \\
\text { reactor }\end{array}$ & $\begin{array}{l}\text { GC/MS-QP } 2010 \text { Shimadzu, equipped with flame ionization } \\
\text { (GC-FID-MS), capillary column (with a diameter of } 0.25 \mathrm{~mm} \\
\text { and length of } 30 \mathrm{~m} \text { coated with a } 0.25 \mu \mathrm{m} \text { film of DB-5), oven } \\
50-300^{\circ} \mathrm{C}, \mathrm{He}(1.26 \mathrm{~mL} / \mathrm{min} \text {, split ratio } 1: 50), \mathrm{m} / \mathrm{z} 40-1000\end{array}$ & $\begin{array}{l}\text { catalytic upgrading of palm } \\
\text { kernel shell pyrolysis vapor }\end{array}$ & [50] \\
\hline centrifugal reactor & $\begin{array}{l}\text { GC-MS/FID Shimadzu QP } 2010 \text { Ultra equipped with a Supelco } \\
\text { Equity } 5 \text { column, oil and aqueous fractions were diluted in } \\
\text { acetone containing } 0.1 \mathrm{~mol} / \mathrm{L} \text { heptane as internal reference, } \\
\text { oven } 80-250^{\circ} \mathrm{C} \text {, split ratio } 1: 80, \mathrm{~m} / \mathrm{z} 20-300\end{array}$ & $\begin{array}{l}\text { upgrading of straw derived } \\
\text { pyrolysis vapors }\end{array}$ & [51] \\
\hline fixed bed tubular reactor & $\begin{array}{l}\text { GC/MS } 7890 \mathrm{~A} / 5975 \mathrm{C} \text { Agilent, bio-oil fraction collected in } \\
\text { the traps was diluted in DCM, HP-5 capillary column, oven } \\
45-290^{\circ} \mathrm{C} \text {, He } 1.2 \mathrm{~mL} / \mathrm{min}\end{array}$ & $\begin{array}{l}\text { catalytic fast pyrolysis of } \\
\text { pomegranate and grape } \\
\text { marcs under vacuum and inert } \\
\text { atmospheres }\end{array}$ & [52] \\
\hline $\begin{array}{l}\text { two-stage fixe bed } \\
\text { reactor }\end{array}$ & $\begin{array}{l}\text { GC/MS 7890A/5975 Agilent with a HP-5MS capillary column } \\
(0.25 \mathrm{~mm} \times 0.25 \mu \mathrm{m} \times 30 \mathrm{~m})\end{array}$ & $\begin{array}{l}\text { upgrading of bio-oil from } \\
\text { catalytic pyrolysis of pretreated } \\
\text { rice husk }\end{array}$ & [53] \\
\hline fixed bed tubular reactor & $\begin{array}{l}\text { GC/MS (Column:HP-5MS ( } 30 \mathrm{~m} \times 0.25 \mathrm{~mm} \mathrm{ID} \times 0.25 \mu \mathrm{m}) \text {, oven } \\
40-270^{\circ} \mathrm{C} \text {, He } 1 \mathrm{~mL} / \mathrm{min}, \mathrm{m} / \mathrm{z} 0-300\end{array}$ & $\begin{array}{l}\text { upgrading of beech sawdust } \\
\text { pyrolysis bio-oil }\end{array}$ & [54] \\
\hline fluidized bed reactor & $\begin{array}{l}\text { GC/MS (Shimadzu QP 2010), HP-Innowax column (oven } \\
60-240^{\circ} \mathrm{C} \text { ) and RTX-5sil MS column (oven } 50-330^{\circ} \mathrm{C} \text { ), He } 1.2 \\
\mathrm{~mL} / \mathrm{min}, 1: 100 \text { split ratio }\end{array}$ & $\begin{array}{l}\text { bio-oil production in fluidized } \\
\text { bed reactor at pilot plant from } \\
\text { sugarcane bagasse by catalytic } \\
\text { fast pyrolysis }\end{array}$ & [55] \\
\hline
\end{tabular}

Table 5 Novel chromatographic methods of bio-oil analysis

\begin{tabular}{|c|c|c|c|}
\hline Method & Equipment & Reaction & Ref. \\
\hline $\begin{array}{l}\text { (1) NanoLC (EI-MS) and (2) } \\
\text { LC x LC }\end{array}$ & $\begin{array}{l}\text { (1) HPLC (Shimadzu, Japan) system coupled to GCMS-QP2010nc Ultra } \\
\text { system } \\
\text { (2) Shimadzu Prominence system (Shimadzu, Italy), consisting of CBM-20A } \\
\text { controller, two LC-20AD dual-plunger parallel-flow pumps (employed } \\
\text { for the 1D separation), LC-20AB solvent delivery module equipped with } \\
\text { two dual-plunger tandem-flow pumps (2D), DGU-20A3 online degasser, } \\
\text { CTO-20A column oven, SIL-20AC autosampler, SPD-M20A photo diode } \\
\text { array detector ( } 2.5 \mu \text { L detector flow cell volume), and LCMS-2020 single } \\
\text { quadrupole mass spectrometer }\end{array}$ & $\begin{array}{l}\text { Fast pyrolysis of } \\
\text { coconut fibers, } \\
\text { sugar cane straw, } \\
\text { and sugar cane } \\
\text { bagasse }\end{array}$ & [57] \\
\hline $\begin{array}{l}\text { CPC fractionation and HPLC } \\
\text { analysis }\end{array}$ & $\begin{array}{l}\text { SCPC } 100+1000 \text { Instrument (Armen Instrument), bio-oil and CPC fractions } \\
\text { are analyzed by HPLC using LC20AD, system (Shimadzu) composed of } \\
\text { binary pump, thermostated autosampler and diode array detector, simple } \\
\text { quadrupole (Shimadzu MS, 2020) was connected after UV detection }\end{array}$ & $\begin{array}{l}\text { Fast pyrolysis of } \\
\text { softwood sawdust }\end{array}$ & [58] \\
\hline $\begin{array}{l}\text { CPC fractionation and } \\
\text { HPLC-UV/MS analysis }\end{array}$ & $\begin{array}{l}\text { CPC experiments were performed on SCPC100 associated to Spot Prep II } \\
\text { from Armen Instrument; } \\
\text { HPLC analysis was conducted using Shimadzu LC } 20 \text { AD (Japan), MS } \\
\text { detection was performed on Shimadzu } 2020 \text { simple quadrupole }\end{array}$ & $\begin{array}{l}\text { Fast pyrolysis of } \\
\text { softwood sawdust }\end{array}$ & [59] \\
\hline
\end{tabular}




\begin{tabular}{ll}
\hline GC/qMS and & GC/qMS analyses were carried out in a Shimadzu QP2010-Plus (Japan), \\
GC x GC/TOFMS & GC x GC/TOFMS analyses were performed using Leco Pegasus IV (LECO, \\
& USA) time of flight mass spectrometric detector coupled to Agilent 6890N \\
& (Agilent Technologies, USA) chromatograph
\end{tabular}

\begin{tabular}{ll}
\hline NanoESI-LC-Q-TOF & liquid chromatographic/mass spectrometric analysis was performed \\
& using 6530 quadrupole time-of-flight (Q-TOF) mass analyzer (Agilent \\
& Technologies, USA) using nanoelectrospray ionization (nanoESI)
\end{tabular}

Headspace-GC-FID/MS) headspace analysis was performed using an Agilent GC 6890 chromatograph with FID and MS detectors in parallel
Fast and
intermediate
pyro lysis of
Eucalyptus sp.
and Picea abies

Fast pyrolysis of $[61]$
pine wood

Fast pyrolysis

of beech wood,

[62]

spruce wood and

wheatstraw

\begin{tabular}{ll}
\hline On-line LC $\times$ LC & (1) first dimension HPLC system (Shimadzu, Japan), second dimension \\
& included two LC-20ADXR pumps \\
& (2) LC Packings ultimate chromatograph (Dionex, Netherlands) and Acquity \\
& UPLC chromato-graph (Waters, USA) \\
\hline GC $\times$ GC/qMS & GC $\times$ GC/qMS (Shimadzu QP2010 Ultra Shimadzu, Japan) equipped with a \\
modulator ZX1-GC $\times$ GC (Zoex, USA)
\end{tabular}

Fast pyrolysis of

[63]

red oak, white

oak, ash and

maple

Fast pyrolysis of
fast pyrolysis of
Lignocel BK40-90
(sawdust from
forest timber)

[64]

Fast pyrolysis of

conifer sawdust

[65]

\begin{tabular}{ll}
\hline SFC and LC/MS & Acquity UPC ${ }^{2}$ instrument (Waters, USA) \\
& Mass spectra were obtained using a LCMS 2020 instrument (Shimadzu, \\
& Japan) equipped with either electrospray ionization (ESI) or atmospheric \\
& pressure chemical ionization (APCI) sources
\end{tabular}

\begin{tabular}{ll}
\hline SEC $\times$ RPLC-UV/IT-TOF MS & $\begin{array}{l}\text { LC analysis (RPLC and SEC) was performed on Shimadzu in strument } \\
\text { (Japan) }\end{array}$
\end{tabular}

FE-HS-GC

\begin{abstract}
automatic headspace sampler (AOC- 5000 Shimadzu), capillary gas chromatograph (GC) with a flame ionization detector (FID, GC-2010 Shimadzu)
\end{abstract}

Fast pyrolysis of softwood sawdust and wheat straw

Fast pyrolysis of eucalyptus mulch in a pilot-scale fluidized-bed reactor of the pretreatment of samples before the main part of the analysis can be applied. According to Staš et al. [56], they can be divided into solvent and solvent-free methods. In the first case, bio-oil is dissolved in one of the solvents (for example - acetone, hexane, diethyl ether or dichloromethane). Owing to that several fractions of compounds differing in chemical properties can be obtained and directed separately to analysis, which makes an interpretation of the chromatographic data easier and more efficient.

On the other hand, fractionation of the analyzed bio-oil can be performed with the use of adsorption chromatography (Liquid-Solid Chromatography - LCS), gel permeation chromatography (GPC) or centrifugal partition chromatography (CPC) [56,58]. In the case of LCS, bio-oil components introduced to chromatographic column are eluted using solvents with increasing polarity. This results in the formation of several fractions having different polar character. GPC allows for the separation of analyzed compounds based on the size of their molecules, while CPC is based on the separation of solutes from the mixture of products of fast pyrolysis of biomass according to the differences in their partitioning coefficients between the mobile and stationary phases [59].

Moreover, solid phase extraction (SPE), molecular distillation (MD) or sample derivatization (SD) can be applied before chromatographic analysis of the products of high temperature decomposition of lignocellulosic feedstock. The latter technique is often used before GC or HPLC analysis. It is based on derivatization reaction (for example - acetylation or trimethylsilylation) which allows for transformation of the analyzed compounds into detectable ones. It is connected with the enhancement of their elution properties, improvement of detector response, change in the volatility, thermal stability or reduction of the strength of adsorption, among others.

Going back to the chromatographic analysis of products of fast pyrolysis of biomass, it should be noted that gas chromatography equipped with mass spectrometric or 
flame ionization detector was the most commonly used method. However, this method suffers from unsatisfactory resolution of chromatograms, peak co-elution, lack of analytical standards, available mass spectra of all identified substances in MS libraries or the presence of nonvolatile compounds in the analyzed mixture and, due to that, difficulties in qualitative and quantitative analysis. In spite of that, Py-GC/MS allows for on-line characterization of formed bio-oil and direct introduction of the sample to the chromatograph, it is not possible to detect high mass compounds due to their condensation in the transfer lines. Moreover, nonvolatile substances or the presence of water may be a reason for deterioration of chromatographic columns. It appears, that mentioned difficulties can be partly overcome by application of more sophisticated methods of the bio-oil analysis [19].

Two-dimensional gas chromatography (GC $\mathrm{x}$ GC) is based on the separation of the analyzed mixture on two capillary columns (the first nonpolar and the second with high or medium polarity) connected with a modulator. In the first step, the bio-oil components are separated according to their boiling points. Then modulator collects substances leaving the first column and directs them to the second one where further analysis is performed. This results in the increase in peak capacity and enhancement of the resolution of chromatographic peaks connected with limitation of coelution. It allows for the increase in the number of identified compounds in comparison to conventional GC-MS measurements. However, detection of the substances having boiling point above $400^{\circ} \mathrm{C}$ is still questionable [56]. Schneider et al. [64] applied two dimensional gas chromatography with fast-quadrupole mass spectrometry detector (GC x GC/qMS) to the analysis of polar compounds which were extracted from the bio-oil formed during fast pyrolysis of sawdust. They confirmed that the use of GC x GC/qMS allowed the identification of about 130 products based on their retention indexes and proved the considerable increase in peak capacity and resolution of chromatograms in comparison with GC/qMS. GC x GC connected with TOFMS detector has been also applied by Torri et al [60] to the characterization of bio-oil formed during fast and intermediate pyrolysis of softwood and hardwood forest industry residues.

The next group of methods of the analysis of bio-oil composition is based on the application of liquid chromatography (LC). One of the drawbacks of this technique is connected with lower separation ability in comparison to that achieved in the case of gas chromatography measurements. However, owing to the application of liquid chromatography, it is possible to detect heavier compounds present in bio-oil, which are not detectable during GC analysis. Moreover, LC allows for analysis of the compounds having higher polarity and gives opportunity to use a wide group of stationary phases possessing various selectivity [65].

Tomasini et al. [57] applied nanoLC coupled with mass spectrometer with mass ionization (EIMS) to determination of the composition of aqueous phase formed in fast pyrolysis of coconut fibers, sugar cane straw, and sugar cane bagasse. The obtained results suggested that owing to the reduction of the volume of eluate achieved by an application of nanoLC column, it was possible to directly introduce the liquid sample to the mass spectrometer. It was connected with considerable reduction in the volume of analyzed material which enabled the generation of vaporized mobile phase volume being compatible with that which could be analyzed by MS detector. On the other hand, the authors proved that the use of two-dimensional liquid chromatography (LC x LC), due to different retention mechanisms in each of the used chromatographic columns, allowed for an increase in peak capacity being responsible for better separation of the analyzed compounds and increase in the number of identified chemicals. Those findings were also confirmed by Le Masle et al. [63].

Literature shows that performance of liquid chromatography in determination of bio-oil composition can be enhanced by the application of centrifugal partition chromatography (CPC) or supercritical fluid chromatography (SFC) $[58,59,65]$. The use of CPC allowed for initial separation of bio-oil into fractions characterized by different solubility without sample loss at moderate temperature which increased overall efficiency of the analysis. On the other hand, SFC can combine the advantages of both gas (for example - low fluid viscosity or easy diffusion of solutes) and liquid chromatography (i.e. - separation of polar compounds, analysis of low volatile molecules) increasing the number of bio-oil components which can be detected with the use of this method.

\subsection{Application of multivariate analysis}

The results presented in the previous chapters confirmed that the interpretation of chromatograms obtained for bio-oil formed in fast pyrolysis of biomass is very difficult. The large amount of data hinders finding valuable information and makes analysis time consuming. It is especially important during investigation of a large number of variables (for example - temperature and time of pyrolysis, type of feedstock and its pretreatment method or effect of catalysts).

Py-GC/MS, the most common method for the analysis of products of fast pyrolysis of biomass, allows for detection 
of hundreds of chemical compounds, but only part of them can be unambiguously identified using the MS detector. This may be connected with co-elution of pyrolysis products on the gas chromatography column, lack of data in MS database or low concentration of considerable group of formed substances [68]. Moreover, the changes in the intensity of signal given by a MS detector may by characteristic for individual components of bio-oil. Therefore, this method is usually used for indication of trends but not for fully quantitative measurements. However, an interpretation of the results obtained with the use of Py-GC/MS can be simplified by the application of multivariate analysis [69,70].

It is known that principal component analysis (PCA) is one of the most popular statistical methods which can be useful for the characterization of the changes in composition of bio-oil formed during high temperature decomposition of lignocellulosic feedstock. The use of PCA allows for the extraction of information from very complex data sets due to the possibility of the transformation of a large number of possibly correlated variables into uncorrelated ones. The number of the latter is much smaller, and they are called principal components.

Xin et al. [68] used PCA for the interpretation of the results of Py-GC/MS study focused on the influence of biomass pretreatment (acid-leaching and torrefaction) on the distribution of products of fast pyrolysis of pinewood. Theauthors identified 45 chemical compounds, which were subsequently subjected to principal component analysis. It was observed that acid-leaching favored formation of levoglucosan and decreased the concentration of ketones in formed bio-oil. On the other hand, torrefaction led to a change in catechols and guaiacols contribution.

PCA was also used for monitoring the composition of bio-oil formed in pyrolysis of cassava rhizome conducted in the presence of various catalysts (zeolites, metal oxides or commercial materials) [71]. In this case, the performed experiments enabled observation of changes in the distribution of aromatic hydrocarbons, phenols, carbonyl products and carboxylic acids, among others.

On the other hand, Reyes-Rivera et al. [72] applied multivariate analysis for the results obtained in Py-GC/ MS studies of spines in Cactaceae. Principal component analysis (PCA), hierarchical clustering analysis (HCA) and hierarchical clustering on the principal components with k-means partition (HCPC) were applied in this case. The combined analysis allowed for identification of a large number of compounds formed during decomposition of the feedstock (derivatives of carbohydrates and lignin or N-compounds) and determination of their abundance patterns. Due to that the classification of lignocellulosic matrix originating from various species was possible.

\section{Summary}

Literature shows that the comprehensive analysis of the composition of bio-oil produced in fast pyrolysis of biomass is very difficult. It is connected with a large number of substances formed during thermal decomposition of lignocellulosic feedstock and their different chemical characteristics. Despite its shortcomings, Py-GC/MS still remains the most popular method of the analysis of fast pyrolysis products. It results from the high versatility of this technique, and possibility of the fast screening of the bio-oil composition. More detailed information on the contribution of selected chemical compounds can be obtained with the use of two-dimensional gas or liquid chromatography. An application of the initial fractionation of the analyzed products before chromatographic analysis may enrich obtained data.

Additionally, the fast development of analytical techniques and methods of data processing should extend the range of the applications of multivariate analysis which can be particularly helpful in determination of the composition of complex matrices consisting of a large number of different components, such as bio-oil derived from the thermal decomposition of lignocellulosic biomass.

\section{References}

[1] Besson M, Gallezot P, Pinel C. Conversion of biomass into chemicals over metal catalysts. Chem Rev. 2014;114:1827-70.

[2] Huber GW, Corma A. Synergies between bio- and oil refineries for the production of fuels from biomass. Angew Chem Int Ed. 2007;46(38):7184-201.

[3] Ruppert AM, Weinberg K, Palkovits R. Hydrogenolysis goes bio: from carbohydrates and sugar alcohols to platform chemicals. Angew Chem Int Ed. 2012;51(11):2564-601.

[4] French R, Czernik S. Catalytic pyrolysis of biomass for biofuels production. Fuel Process Technol. 2010;91:25-32.

[5] Bulushev DA, Ross JR. Catalysis for conversion of biomass to fuels via pyrolysis and gasification: a review. Catal Today. 2011;171:1-13.

[6] Chen X, Che Q, Li S, Liu Z, Yang H, Chen Y, et al. Recent developments in lignocellulosic biomass catalytic fast pyrolysis: strategies for the optimization of bio-oil quality and yield. Fuel Process Technol. 2019;196:106180.

[7] Yaman S. Pyrolysis of biomass to produce fuels and chemical feedstocks. Energy Convers Manage. 2004;45(5):651-71.

[8] Isahak WN, Hisham MW, Yarmo MA, Hin TY. A review on bio-oil production from biomass by using pyrolysis method. Renew Sustain Energy Rev. 2012;16(8):5910-23.

[9] Wang K, Kim KH, Brown RC. Catalytic pyrolysis of individual components of lignocellulosic biomass. Green Chem. 2014;16:727-35.

[10] Wang K, Johnston PA, Brown RC. Comparison of in-situ and ex-situ catalytic pyrolysis in a micro-reactor system. Bioresour Technol. 2014;173:124-31. 
[11] Navarro RM, Peña MA, Fierro JL. Hydrogen production reactions from carbon feedstocks: fossil fuels and biomass. Chem Rev. 2007;107:3952-91.

[12] Minowa T, Ogi T. Hydrogen production from cellulose using a reduced nickel catalyst. Catal Today. 1998;45:411-6.

[13] Collard FX, Blin J. A review on pyrolysis of biomass constituents: mechanisms and composition of the products obtained from the conversion of cellulose, hemicelluloses and lignin. Renew Sustain Energy Rev. 2014;38:594-608.

[14] Bridgwater AV. Review of fast pyrolysis of biomass and product upgrading. Biomass Bioenergy. 2012;38:68-94.

[15] Grams J, Ruppert A. Development of heterogeneous catalysts for thermo-chemical conversion of lignocellulosic biomass. Energies. 2017;10:545-70.

[16] Jeon M, Jeon J, Suh DJ, Park SH, Sa YJ, Joo SH, et al. Catalytic pyrolysis of biomass components over mesoporous catalysts using Py-GC/MS. Catal Today. 2013;204:170-8.

[17] Stefanidis SD, Kalogiannis KG, Iliopoulou EF, Lappas AA, Pilavachi P. In-situ upgrading of biomass pyrolysis vapors: catalyst screening on a fixed bed reactor. Bioresour Technol. 2011;102:8261-7.

[18] Chandran R, Kaliaperumal R, Balakrishnan S, Britten AJ, Maclnnis J, Mkandawire M. Characteristics of bio-oil from continuous fast pyrolysis of Prosopis juliflora. Energy. 2020;190:116387.

[19] Kanaujia PK, Sharma YK, Garg MO, Tripathi D, Singh R. Review of analytical strategies in the production and upgrading of bio-oils derived from lignocellulosic biomass. J Anal Appl Pyrolysis. 2014;105:55-74.

[20] Wang S, Guo X, Liang T, Zhou Y, Luo Z. Mechanism research on cellulose pyrolysis by Py-GC/MS and subsequent density functional theory studies. Bioresour Technol. 2010;104:722-8.

[21] Sun T, Li Z, Zhang Z, Wang Z, Yang S, Yang Y, et al. Fast corn stalk pyrolysis and the influence of catalysts on product distribution. Bioresour Technol. 2020;301:122739.

[22] Braga RM, Melo DM, Sobrinho EV, Barros JM, Melo MA, Carvalho AF, et al. Catalytic upgrading of Elephant grass (Pennisetum purpureum Schum) pyrolysis vapor using WO supported on RHA and RHA-MCM-41. Catal Today. 2017;279:224-32.

[23] Lu Q, Zhou M, Li W, Wang X, Cui M, Yang Y. Catalytic fast pyrolysis of biomass with noble metal-like catalysts to produce high-grade bio-oil: analytical Py-GC/MS study. Catal Today. 2018;302:169-79.

[24] Xue Z, Zhong Z, Zhang B, Xu C. Performance of catalytic fast pyrolysis using $\alpha-\mathrm{Al}_{2} \mathrm{O}_{3}$ catalyst with compound modification of $\mathrm{ZrO}_{2}$ and $\mathrm{CeO}_{2}$. Catalysts. 2019;9:849.

[25] Lu Q, Zhang Z, Dong C, Zhu X. Catalytic upgrading of biomass fast pyrolysis vapors with nano metal oxides: an analytical Py-GC/MS study. Energies. 2010;3:1805-20.

[26] Liu Y, Leahy JJ, Grams J, Kwapinski W. Hydro-pyrolysis and catalytic upgrading of biomass and its hydroxy residue fast pyrolysis vapors. Energies. 2019;12:3474.

[27] Melligan F, Hayes MH, Kwapinski W, Leahy JJ. Hydro-pyrolysis of biomass and online catalytic vapor upgrading with Ni-ZSM-5 and Ni-MCM-41. Energy Fuels. 2012;26:6080-90.

[28] Zhang H, Zheng J, Xiao R, Jia Y, Shen D, Jin B, et al. Study on pyrolysis of pine sawdust with solid base and acid mixed catalysts by thermogravimetry-Fourier transform infrared spectroscopy and pyrolysis-gas chromatography/mass spectrometry. Energy Fuels. 2014;28:4294-9.

[29] Lu Q, Zhang Y, Tang Z, Li W, Zhu X. Catalytic upgrading of biomass fast pyrolysis vapors with titania and zirconia/titania based catalysts. Fuel. 2010;89:2096-103.

[30] Zhang B, Zhong Z, Wang X, Ding K, Song Z. Catalytic upgrading of fast pyrolysis biomass vapors over fresh, spent and regenerated ZSM-5 zeolites. Fuel Process Technol. 2015;138:430-4.

[31] Lu Q, Guo H, Zhou M, Cui M, Dong C, Yang Y. Selective preparation of monocyclic aromatic hydrocarbons from catalytic cracking of biomass fast pyrolysis vapors over $\mathrm{Mo}_{2} \mathrm{~N} /$ HZSM-5 catalyst. Fuel Process Technol. 2018;173:134-42.

[32] Lu Q, Tang Z, Zhang Y, Zhu X. Catalytic upgrading of biomass fast pyrolysis vapors with Pd/SBA-15 catalysts. Ind Eng Chem Res. 2010;49:2573-80.

[33] Harman-Ware AE, Crocker M, Kaur AP, Meier MS, Kato D, Lynn B. Pyrolysis-GC/MS of sinapyl and coniferyl alkohol. J Anal Appl Pyrolysis. 2013;99:161-9.

[34] Zhang X, Sun L, Chen L, Xie X, Zhao B, Si H, et al. Comparison of catalytic upgrading of biomass fast pyrolysis vapors over $\mathrm{CaO}$ and $\mathrm{Fe}(\mathrm{III}) / \mathrm{CaO}$ catalysts. J Anal Appl Pyrolysis. 2014;108:35-40.

[35] Zhang L, Li K, Zhu X. Study on two-step pyrolysis of soybean stalk by TG-FTIR and Py-GC/MS. J Anal Appl Pyrolysis. 2017;127:91-8.

[36] Gupta J, Papadikis K, Kozhevnikov IV, Konysheva EY. Exploring the potential of red mud and beechwood co-processing for the upgrading of fast pyrolysis vapours. J Anal Appl Pyrolysis. 2017;128:35-43.

[37] Ukaew S, Schoenborn J, Klemetsrud B, Shonnard DR. Effects of torrefaction temperature and acid pretreatment on the yield and quality of fast pyrolysis bio-oil from rice straw. J Anal Appl Pyrolysis. 2018;129:112-22.

[38] Zhang S, Zhu S, Zhang H, Chen T, Xiong Y. Catalytic fast pyrolysis of rice husk: effect of coupling leaching with torrefaction pretreatment. J Anal Appl Pyrolysis. 2018;133:91-6.

[39] Baimoldina A, Papadikis K, Konysheva EY. Diverse impact of $\alpha-\mathrm{Fe}_{2} \mathrm{O}_{3}$ with nano/micro-sized shapes on the catalytic fast pyrolysis of pinewood: Py-GC/MS study. J Anal Appl Pyrolysis. 2019;139:145-55.

[40] Vichaphund S, Wimuktiwan P, Sricharoenchaikul V, Atong D. In situ catalytic pyrolysis of Jatropha wastes using ZSM-5 from hydrothermal alkaline fusion of fly ash. J Anal Appl Pyrolysis. 2019;139:156-66.

[41] Vichaphund S, Sricharoenchaikul V, Atong D. Selective aromatic formation from catalytic fast pyrolysis of Jatropha residues using ZSM-5 prepared by microwave-assisted synthesis. J Anal Appl Pyrolysis. 2019;141:104628.

[42] Vichaphund S, Aht-ong D, Sricharoenchaikul V, Atong D. Catalytic upgrading pyrolysis vapors of Jatropha waste using metal promoted ZSM- 5 catalysts: an analytical PY-GC/MS. Renew Energy. 2014;65:70-7.

[43] Santana JA Junior, Menezes AL, Ataide CH. Catalytic upgrading of fast hydropyrolysis vapors from industrial Kraft lignins using ZSM-5 zeolite and HY-340 niobic acid. J Anal Appl Pyrolysis. 2019;144:104720. 
[44] Usino DO. Supriyanto, Ylitervo P, Pettersson A, Richards T. Influence of temperature and time on initial pyrolysis of cellulose and Dylan. J Anal Appl Pyrolysis. 2020;147:104782.

[45] Melligan F, Hayes MH, Kwapinski W, Leahy JJ. A study of hydrogen pressure during hydropyrolysis of Miscanthus $\mathrm{X}$ giganteus and online catalytic vapour upgrading with $\mathrm{Ni}$ on ZSM-5. J Anal Appl Pyrolysis. 2013;103:369-77.

[46] Grams J, Niewiadomski M, Ruppert AM, Kwapinski W. Catalytic performance of a $\mathrm{Ni}$ catalyst supported on $\mathrm{CeO}_{2}, \mathrm{ZrO}_{2}$ and $\mathrm{CeO}_{2}-\mathrm{ZrO}_{2}$ in the upgrading of cellulose fast pyrolysis vapors. C R Chim. 2015;18:1223-8.

[47] Grams J, Niewiadomski M, Ruppert AM, Kwapinski W. Influence of Ni catalyst support on the product distribution of cellulose fast pyrolysis vapors upgrading. J Anal Appl Pyrolysis. 2015;113:557-63.

[48] Azeez AM, Meier D, Odermatt J, Willner T. Fast pyrolysis of African and European lignocellulosic biomasses using Py-GC/MS and fluidized bed reactor. Energy Fuels. 2010;24:2078-85.

[49] Amutio M, Lopez G, Alvarez J, Olazar M, Bilbao J. Fast pyrolysis of eucalyptus waste in a conical spouted bed reactor. Bioresour Technol. 2015;194:225-32.

[50] Asadieraghi M, Daud WM. In-situ catalytic upgrading of biomass pyrolysis vapor: using a cascade system of various catalysts in a multi-zone fixed bed reactor. Energy Convers Manage. 2015;101:151-63.

[51] Eschenbacher A, Jensen PA, Henriksen UB, Ahrenfeldt J, Li C, Duus JØ, et al. Impact of ZSM-5 Deactivation on Bio-Oil Quality during Upgrading of Straw Derived Pyrolysis Vapors. Energy Fuels. 2019;33:397-412.

[52] Ateş F, Büyüktuncer H, Yaşar B, Işık A, Biricik G, Koparal AS. Comparison of non-catalytic and catalytic fast pyrolysis of pomegranate and grape marcs under vacuum and inert atmospheres. Fuel. 2019;255:115788.

[53] Zhang S, Zhang H, Liu X, Zhu S, Hu L, Zhang Q. Upgrading of bio-oil from catalytic pyrolysis of pretreated rice husk over Fe-modified ZSM-5 zeolite catalyst. Fuel Process Technol. 2018;175:17-25.

[54] Saracoglu E, Uzun BB, Apaydın-Varol E. Upgrading of fast pyrolysis bio-oil over Fe modified ZSM-5 catalyst to enhance the formation of phenolic compounds. Int J Hydrogen Energy. 2017;4(2):21476-86.

[55] Osorio J, Chejne F. Bio-oil production in fluidized bed reactor at pilot plant from sugarcane bagasse by catalytic fast pyrolysis. Waste Biomass Valoriz. 2019;10:187-95.

[56] Staš M, Kubička D, Chudoba J, Pospíšil M. Overview of analytical methods used for chemical characterization of pyrolysis bio-oil. Energy Fuels. 2014;28:385-402.

[57] Tomasini D, Cacciola F, Rigano F, Sciarrone D, Donato P, Beccaria $\mathrm{M}$, et al. Complementary analytical liquid chromatography methods for the characterization of aqueous phase from pyrolysis of lignocellulosic biomasses. Anal Chem. 2014;86:11255-62.

[58] Le Masle A, Santin S, Marlot L, Chahen L, Charon N. Centrifugal partition chromatography a first dimension for biomass fast pyrolysis oil analysis. Anal Chim Acta. 2018;1029:116-24.

[59] Dubuis A, Le Masle A, Chahen L, Destandau E, Charon N. Centrifugal partition chromatography as a fractionation tool for the analysis of lignocellulosic biomass products by liquid chromatography coupled to mass spectrometry. J Chromatogr A. 2019;1597:159-66.

[60] Torri ID, Paasikallio V, Faccini CS, Huff R, Caramão EB, Sacon $\mathrm{V}$, et al. Bio-oil production of softwood and hardwood forest industry residues through fast and intermediate pyrolysis and its chromatographic characterization. Bioresour Technol. 2016;200:680-90.

[61] Joseph J, Rasmussen MJ, Fecteau JP, Kim S, Lee H, Tracy KA, et al. Compositional changes to low water content bio-oils during aging: an NMR, GC/MS, and LC/MS Study. Energy Fuels. 2016;30:4825-40.

[62] Charon N, Ponthus J, Espinat D, Broust F, Volle G, Valette J, et al. Multi-technique characterization of fast pyrolysis oils. J Anal Appl Pyrolysis. 2015;116:18-26.

[63] Le Masle A, Angot D, Gouin C, D’Attoma A, Ponthus J, Quignard A, et al. Development of on-line comprehensive two-dimensional liquid chromatography method for the separation of biomass compounds. J Chromatogr A. 2014;1340:90-8.

[64] Schneider JK, da Cunha ME, dos Santos AL, Maciel GP, Brasil $M C$, Pinho AR, et al. Comprehensive two dimensional gas chromatography with fast-quadrupole mass spectrometry detector analysis of polar compounds extracted from the bio-oil from the pyrolysis of sawdust. J Chromatogr A. 2014;1356:236-40.

[65] Crepier J, Le Masle A, Charon N, Albrieux F, Heinisch S. Development of a supercritical fluid chromatography method with ultraviolet and mass spectrometry detection for the characterization of biomass fast pyrolysis bio oils. I Chromatogr A. 2017;1510:73-81.

[66] Dubuis A, Le Masle A, Chahen L, Destandau E, Charon N. Off-line comprehensive size exclusion chromatography $\times$ reversed-phase liquid chromatography coupled to high resolution mass spectrometry for the analysis of lignocellulosic biomass products. J Chromatogr A. 2020;1609:460505.

[67] Lima NK, Lopes AR, Guerrero PG Jr, Yamamoto Cl, Hansel FA. Determination of volatile organic compounds in eucalyptus fast pyrolysis bio-oil by full evaporation headspace gas chromatography. Talanta. 2018;176:47-51.

[68] Xin X, Pang S, Mercader FM, Torr KM. The effect of biomass pretreatment on catalytic pyrolysis products of pine wood by Py-GC/MS and principal component analysis. J Anal Appl Pyrolysis. 2019;138:145-53.

[69] Mohabeer C, Abdelouahed L, Marcotte S, Taouk B. Comparative analysis of pyrolytic liquid products of beech wood, flax shives and woody biomass components. J Anal Appl Pyrolysis. 2017;127:269-77.

[70] Eide I, Neverdal G. Fingerprinting bio-oils from lignocellulose and comparison with fossil fuels. Energy Fuels. 2014;28:2617-23.

[71] Pattiya A, Titiloye JO, Bridgwater AV. Evaluation of catalytic pyrolysis of cassava rhizome by principal component analysis. Fuel. 2010;89:244-53.

[72] Reyes-Rivera J, Solano E, Terrazas T, Soto-Hernandez M, Arias S,. Almanza-Arjona YC, Polindara-Garcia LA. Classification of lignocellulosic matrix of spines in Cactaceae by Py-GC/ MS combined with omic tools and multivariate analysis: A chemotaxonomic approach. J. Anal. Appl. Pyrol. 2020, published ahead of print; DOI: https://doi.org/10.1016/j. jaap.2020.104796. 